that writers are afraid of reviewers, and uncertain as to what evidence they aspire to reach. They include therefore ' small print ' material of interest only to specialists, as well as basic material which all medical men and students should know. It is not strange therefore that the student when he first enters hospital should ask, without getting a reply: "What is the curriculum? What must I get to know and understand?

This book is refreshingly short, refreshingly different in its classification of diseases, and refreshingly well illustrated. Some of the classifications will worry purists: 'Abnormal Inflammation' presents a problem in semantics, and 'Mechanical breakdown of transport in the body ' brings together acute intestinal obstruction and Christmas disease. But this matters little; the text is clear and up to date, and blessedly concise.

References are all to the point, but not comprehensive. However, if a normally industrious student reads and understands and remembers what is here, he will be fully equipped to face the examiner, and understand the annotations in the Lancet.

\section{MEDICAL HELMINTHOLOGY}

By J. M. Watson. Pp. xi +500 , illustrated. London: Baillière, Tindall \& Cox. I960. 84s.

This notable work is written by one who, after a long period of work in Baghdad and Beirut, holds the directorship of the Commonwealth Bureau of Helminthology and who is Senior Helminthologist at the Wellcome Laboratories of Tropical Medicine in London. With this background we expect and we receive a most complete encylopaedia of helminthology, including a historical review, chapters on physiology, immunity and ecology; there is even an appendix on recent advances which many authors would have left for the second edition.

The author, as an officer of the World Health Organization, is deeply concerned with the control of helminth infestation. He reminds us that six out of seven helminthic infections are due to ineffective insulation of man from his own excretory products; like most tropical diseases, helminthiasis is the result of poor or absent hygiene and therefore an entirely soluble problem.

Perhaps, now that malaria is under control, the next great humane service will be the control of these parasites. The life-cycles of these beasties are fantastic; it sometimes seems incredible that man should have so intimately explored them.

This great work will undoubtedly inspire young workers into whose fortunate hands it falls to follow in the footsteps of the great British school of helminthologists.

\section{A PRACTICE OF ANAESTHESIA}

By W. D. Wylie and H. C. Churchill-Davidson. Pp. xvi + 1056, illustrated. London: LloydLuke (Medical Books) Ltd. 1959. 105s.

This is a large book, and full of good things.

It is subdivided according to physiological systems. This is an unusual plan for a textbook of anaesthesia, and it leads to some inconsistencies and repetitions.

The greater part of the book-whose compilation represents much labour - is by Wylie and ChurchillDavidson, but seven other authors have also contributed, and it may be regarded as a compendium of anaesthetic practice at St. Thomas's Hospital, which has long been recognised for its good work in this field.

The general standard is high but there are lapses here and there. The section on oxygen therapy is sketchy, and no mention is made of the concentrations achieved or of methods of measuring them. In the section on lung function, the Pappenheimer nomenclature is adopted, but its notation is not.

There is a well written section on cardiovascular physiology, and the difficult subject of neuromuscular block is excellently treated.

There are very few omissions, and a full index helps the reader to find what he wants in a book whose arrangement is of an unfamiliar pattern. The printing and format are unexceptionable, and the book can be strongly recommended.

\section{TEXTBOOK OF GYNAECOLOGY}

By J. H. PeEl, M.A., B.M., B.Ch.(Oxon.), F.R.C.S., F.R.C.O.G. 5th edition. Pp. 49I $+x v$, illustrated. London: William Heinemann (Medical Books) Ltd. 1960. 30s.

If one seeks the reasons for the popularity of Sir John Peel's book, for it has now gone through five editions in 17 years, one finds them quickly. It is eminently readable. It fulfils all the requirements for the qualifying examinations for gynaecology. Its price, at 30 s., is cheap. Now it is thoroughly up to date.

In 1943, when Mr. Peel first wrote his book, it was based on the skeleton of an earlier textbook and just occasionally, one is aware of this, because there are still retained one or two of the early illustrations and photographs. They do not help greatly in the understanding of the subject, but show the tradition that has been handed on.

In the main, the information that is necessary to satisfy the examiners for the conjoint boards and the university qualifying examinations is presented succinctly. I particularly like the sections on physiology, dealing simply with the biochemical aspects of the endocrine functions, and one or two of the new illustrations, such as vaginal smear of carcinoma in situ.

The general layout of the book is pleasing and it will certainly continue to sell. 